\title{
Vitamin D Deficiency at Mid-Pregnancy Is Associated with a Higher Risk of Postpartum Glucose Intolerance in Women with Gestational Diabetes Mellitus
}

\author{
Kyung-Soo Kim ${ }^{1}$, Seok Won Park ${ }^{2}$, Yong-Wook Cho ${ }^{1}$, Soo-Kyung Kim ${ }^{1}$ \\ ${ }^{1}$ Department of Internal Medicine, CHA Bundang Medical Center, CHA University, Seongnam; ${ }^{2}$ Department of Internal \\ Medicine, Yonsei University College of Medicine, Seoul, Korea
}

Background: To evaluate the association between serum 25-hydroxyvitamin D (25(OH)D) at mid-pregnancy and postpartum glucose intolerance in women with gestational diabetes mellitus (GDM).

Methods: We enrolled 348 pregnant women diagnosed with GDM from August 2012 to October 2016. We measured serum 25(OH) D levels at mid-pregnancy and carried out a 75-g oral glucose tolerance test at 6 to 12 weeks after delivery. Vitamin D deficiency was defined as serum $25(\mathrm{OH}) \mathrm{D}<20 \mathrm{ng} / \mathrm{mL}$.

Results: The prevalence of vitamin D deficiency was 76.7\% $(n=267)$. Women with vitamin D deficiency had a higher prevalence of postpartum glucose intolerance than did those without vitamin D deficiency ( $48.7 \%$ vs. $32.1 \%, P=0.011)$. Serum $25(\mathrm{OH}) \mathrm{D}$ level was negatively correlated with hemoglobin A1c at antepartum and postpartum period (antepartum: $r=-0.186, P=0.001$; postpartum: $r=-0.129, P=0.047)$. Homeostasis model assessment of $\beta$-cell function was positively correlated with serum 25(OH)D level only postpartum $(r=0.138, P=0.035)$. The risk of postpartum glucose intolerance was 2.00 times $(95 \%$ confidence interval, 1.13 to 3.55$)$ higher in women with vitamin D deficiency than in those without vitamin D deficiency $(P=0.018)$.

Conclusion: In women with GDM, vitamin D deficiency at mid-pregnancy is associated with an elevated risk of postpartum glucose intolerance.

Keywords: Diabetes, gestational; Glucose intolerance; Postpartum period; Vitamin D deficiency

\section{INTRODUCTION}

Although the causality of this relationship is uncertain, vitamin D deficiency is associated with type 2 diabetes and metabolic syndrome [1-4]. Vitamin D is fat-soluble and is essential for bone and calcium metabolism [5,6]. It is also well-known that vitamin $\mathrm{D}$ is involved in glucose homeostasis by facilitating the action and secretion in insulin [7,8]. Many studies have shown

Received: 15 July 2019, Revised: 3 November 2019,

Accepted: 23 December 2019

Corresponding author: Soo-Kyung Kim

Department of Internal Medicine, CHA Bundang Medical Center, CHA

University, 59 Yatap-ro, Bundang-gu, Seongnam 13496, Korea

Tel: +82-31-780-5156, Fax: +82-31-780-5208, E-mail: imdrksk@cha.ac.kr that either insulin release and insulin sensitivity could be improved or type 2 diabetes could be prevented by vitamin D supplements [9-11]. However, randomized clinical trials for vitamin D supplements have shown inconsistent results [12,13].

Gestational diabetes mellitus (GDM) is diabetes that is newly diagnosed in the second or third trimester of pregnancy that is not clearly either preexisting type 1 or type 2 diabetes and its prevalence has been increasing worldwide [14-16]. Vitamin D

Copyright $\odot 2020$ Korean Endocrine Society

This is an Open Access article distributed under the terms of the Creative Commons Attribution Non-Commercial License (https://creativecommons.org/ licenses/by-nc/4.0/) which permits unrestricted non-commercial use, distribution, and reproduction in any medium, provided the original work is properly cited. 
deficiency is common in pregnant women and is recognized as an emerging issue in global health [17-19]. Recently gathered evidence suggests that vitamin D deficiency in the two first trimesters of pregnancy increase the risk of insulin resistance and developing GDM [20-22]. GDM is characterized by compensatory failure of insulin secretion in response to increased insulin resistance during pregnancy. In addition, increased insulin resistance and decreased insulin secretion due to vitamin $\mathrm{D}$ deficiency during mid-pregnancy might continuously influence on postpartum glucose intolerance [23-25]. Nowadays, postpartum monitoring for glucose intolerance has been increasing in importance, because GDM is associated with an increased risk for developing type 2 diabetes after delivery [25,26]. However, there are few studies that have examined the effect of vitamin D deficiency at mid-pregnancy on postpartum glucose intolerance in patients with GDM. The aim of this study was to evaluate the association between serum 25-hydroxyvitamin D $(25(\mathrm{OH}) \mathrm{D})$ at mid-pregnancy and postpartum glucose intolerance in women with GDM.

\section{METHODS}

\section{Participants and design}

We conducted this observational study in CHA Bundang Medical Center (Seongnam, Korea) from August 2012 to October 2016, enrolling 348 pregnant women diagnosed with GDM and aged $\geq 20$ years. We used a 'two-step' approach for diagnosis of GDM. First, we used a 1-hour 50-g glucose load test as screening at 24 to 28 weeks of gestation. We offered a 3-hour 100-g oral glucose tolerance test (OGTT) to woman who had a 1-hour post-load plasma glucose level $>140 \mathrm{mg} / \mathrm{dL}$. According to the Carpenter and Coustan criteria, the diagnosis of GDM can be made if at least two of the four plasma glucose levels (measured fasting and 1, 2, and 3 hours after the 100-g OGTT) were met or exceeded. We excluded women who were known to have had type 1 or type 2 diabetes before pregnancy, thyroid disorders, twin pregnancy, and a history of taking vitamin D supplements during pregnancy.

At 24 to 32 weeks of gestation (baseline visit), we carried out anthropometric assessments, measured blood pressure, and did laboratory tests, including fasting glucose, hemoglobin A1c (HbA1c), lipid profiles, and serum 25(OH)D level for all study participants. We collected medical histories from medical records. These women were given medical nutrition therapy and/ or insulin treatment during their antenatal follow-up. We evaluated postpartum glycemic status by 75-g OGTT at 6 to 12 weeks after delivery. We defined glucose intolerance as fasting plasma glucose $(\mathrm{FPG}) \geq 100 \mathrm{mg} / \mathrm{dL}$ or 2-hour plasma glucose $\geq 140 \mathrm{mg} / \mathrm{dL}$. This study was approved by the Institutional Review Board of CHA Bundang Medical Center at CHA University School of Medicine (2017-08-004), and we obtained informed consent from all study participants.

\section{Clinical and laboratory measurements}

Height and weight were measured for all subjects when they were wearing minimal clothing and no shoes. We measured blood pressure by trained nurses using automatic sphygmomanometer while the participants were seated for 10 minutes. Serum $25(\mathrm{OH}) \mathrm{D}$ levels were measured by the chemiluminescence immunoassay (ADVIA Centaur XP, Siemens Healthcare, Tarrytown, NY, USA). We measured plasma glucose, total cholesterol, triglyceride, and high density lipoprotein cholesterol (HDLC) using a Hitachi 7600 analyzer (Hitachi, Tokyo, Japan). We measured HbA1c using high-performance liquid chromatography (before May 2013, Bio-Rad Variant II, Hercules, CA, USA; after May 2013, Tosoh G8, San Francisco, CA, USA). We assessed C-peptide and insulin by the chemiluminescence immunoassay (Roche Diagnostic GmbH, Mannheim, Germany). We carried out the homeostasis model assessment of insulin resistance (HOMA-IR) and $\beta$-cell function (HOMA- $\beta$ ) according to suggested formulas [27].

\section{Statistical analysis}

Data for categorical factors are reported as percentages, and continuous variables are presented as the mean $\pm \mathrm{SD}$. Vitamin D deficiency was defined as serum $25(\mathrm{OH}) \mathrm{D}<20 \mathrm{ng} / \mathrm{mL}$. We grouped seasons depending on the date of sample collection for serum 25(OH)D analysis (spring, March to May; summer, June to August; autumn, September to November; winter, December to February). All statistical analyses were done using SPSS version 19.0 software (IBM Co., Armonk, NY, USA).

\section{RESULTS}

Table 1 shows the baseline characteristics of the women with GDM at mid-pregnancy. The mean age was 33.1 years and the gestational weeks were 27.8 weeks. Among the 348 women with GDM, 267 women (76.7\%) were vitamin D deficiency at baseline. Women with vitamin D deficiency had higher prepregnancy body mass index (BMI), pre-pregnancy weight, midpregnancy weight, weight gain, blood pressure (systolic and diastolic), $\mathrm{HbA1c}$, triglyceride, fasting insulin, and HOMA- $\beta$ than 
Table 1. Baseline Characteristics of Women with Gestational Diabetes Mellitus According to Serum 25(OH)D Level at Mid-Pregnancy

\begin{tabular}{|c|c|c|c|c|}
\hline Characteristic & Total & Serum $25(\mathrm{OH}) \mathrm{D}<20 \mathrm{ng} / \mathrm{dL}$ & Serum $25(\mathrm{OH}) \mathrm{D} \geq 20 \mathrm{ng} / \mathrm{dL}$ & $P$ value \\
\hline Number & $348(100.0)$ & $267(76.7)$ & $81(23.3)$ & \\
\hline Age, yr & $33.1 \pm 3.5$ & $33.1 \pm 3.6$ & $33.2 \pm 3.0$ & 0.870 \\
\hline Pre-pregnancy BMI, kg/m² & $22.3 \pm 3.5$ & $22.7 \pm 3.6$ & $21.0 \pm 2.6$ & $<0.001$ \\
\hline Pre-pregnancy weight, kg & $58.0 \pm 10.1$ & $58.8 \pm 10.4$ & $55.2 \pm 8.7$ & 0.005 \\
\hline Mid-pregnancy weight, kg & $64.9 \pm 10.1$ & $66.0 \pm 10.2$ & $61.3 \pm 8.9$ & $<0.001$ \\
\hline Weight gain, $\mathrm{kg}$ & $6.9 \pm 3.9$ & $7.2 \pm 4.0$ & $6.1 \pm 3.3$ & 0.028 \\
\hline History of GDM & $10(2.9)$ & $9(3.4)$ & $1(1.2)$ & 0.464 \\
\hline Family history of diabetes & $122(35.1)$ & $88(33.0)$ & $34(42.0)$ & 0.145 \\
\hline Parity (\% primiparous) & $203(58.3)$ & $154(57.7)$ & $49(60.5)$ & 0.700 \\
\hline Gestational weeks & $27.8 \pm 1.7$ & $27.8 \pm 1.8$ & $27.8 \pm 1.4$ & 0.994 \\
\hline Season & & & & 0.139 \\
\hline Spring & $90(25.9)$ & $66(24.7)$ & $24(29.6)$ & \\
\hline Summer & $96(27.6)$ & $71(26.6)$ & $25(30.9)$ & \\
\hline Autumn & $97(27.9)$ & $73(27.3)$ & $24(29.6)$ & \\
\hline Winter & $65(18.7)$ & $57(21.3)$ & $8(9.9)$ & \\
\hline Systolic blood pressure, $\mathrm{mm} \mathrm{Hg}$ & $112.3 \pm 13.9$ & $113.5 \pm 14.1$ & $108.4 \pm 12.6$ & 0.002 \\
\hline Diastolic blood pressure, $\mathrm{mm} \mathrm{Hg}$ & $67.9 \pm 9.9$ & $68.8 \pm 10.2$ & $65.1 \pm 8.5$ & 0.001 \\
\hline $\mathrm{FPG}, \mathrm{mg} / \mathrm{dL}$ & $88.8 \pm 10.4$ & $89.0 \pm 9.9$ & $88.2 \pm 11.9$ & 0.558 \\
\hline $\mathrm{HbA1c}, \%$ & $5.2 \pm 0.4$ & $5.3 \pm 0.4$ & $5.1 \pm 0.3$ & 0.001 \\
\hline Total cholesterol, mg/dL & $246.1 \pm 41.2$ & $246.8 \pm 42.9$ & $243.9 \pm 35.3$ & 0.581 \\
\hline Triglyceride, $\mathrm{mg} / \mathrm{dL}$ & $201.0 \pm 84.0$ & $206.7 \pm 89.1$ & $182.0 \pm 61.2$ & 0.020 \\
\hline HDL-C, mg/dL & $72.6 \pm 12.6$ & $72.7 \pm 12.8$ & $72.5 \pm 12.1$ & 0.910 \\
\hline Albumin, mg/dL & $3.79 \pm 0.23$ & $3.78 \pm 0.24$ & $3.80 \pm 0.22$ & 0.436 \\
\hline Fasting C-peptide, $\mathrm{ng} / \mathrm{mL}$ & $1.67 \pm 0.76$ & $1.70 \pm 0.74$ & $1.54 \pm 0.81$ & 0.102 \\
\hline Fasting insulin, $\mu \mathrm{U} / \mathrm{mL}$ & $6.67 \pm 4.33$ & $6.95 \pm 4.37$ & $5.75 \pm 4.12$ & 0.029 \\
\hline HOMA-IR & $1.52 \pm 1.12$ & $1.57 \pm 1.10$ & $1.32 \pm 1.17$ & 0.080 \\
\hline HOMA- $\beta$ & $98.3 \pm 62.3$ & $102.8 \pm 67.2$ & $83.5 \pm 38.8$ & 0.001 \\
\hline Plasma glucose at 50-g OGTT, mg/dL & $170.9 \pm 22.2$ & $170.8 \pm 22.5$ & $171.3 \pm 21.5$ & 0.856 \\
\hline \multicolumn{5}{|l|}{ 100-g OGTT } \\
\hline 0 min plasma glucose, $\mathrm{mg} / \mathrm{dL}$ & $96.7 \pm 12.2$ & $96.4 \pm 11.9$ & $97.4 \pm 13.2$ & 0.545 \\
\hline 60 min plasma glucose, $\mathrm{mg} / \mathrm{dL}$ & $193.5 \pm 28.2$ & $192.4 \pm 28.4$ & $196.9 \pm 28.4$ & 0.204 \\
\hline 120 min plasma glucose, $\mathrm{mg} / \mathrm{dL}$ & $174.0 \pm 25.1$ & $173.1 \pm 25.0$ & $176.7 \pm 25.4$ & 0.258 \\
\hline 180 min plasma glucose, $\mathrm{mg} / \mathrm{dL}$ & $144.5 \pm 27.6$ & $145.2 \pm 26.5$ & $141.9 \pm 30.9$ & 0.338 \\
\hline Serum 25(OH)D & $14.3 \pm 8.2$ & $10.8 \pm 4.9$ & $26.0 \pm 5.2$ & $<0.001$ \\
\hline
\end{tabular}

Values are expressed as number $(\%)$ or mean \pm standard deviation.

25(OH)D, 25-hydroxyvitamin D; BMI, body mass index; GDM, gestational diabetes mellitus; FPG, fasting plasma glucose; HbA1c, hemoglobin A1c; HDL-C, high density lipoprotein cholesterol; HOMA-IR, homeostasis model assessment of insulin resistance; HOMA- $\beta$, homeostasis model assessment of $\beta$-cell function; OGTT, oral glucose tolerance test.

did those without vitamin D deficiency. There were no significant differences in age, history of GDM, family history of diabetes, parity, gestational weeks, season, FPG, total cholesterol,
HDL-C, albumin, fasting C-peptide, HOMA-IR, and the results of 50-g and 100-g OGTT between women with and without vitamin D deficiency. 
Pregnancy outcomes such as preterm delivery, Cesarean section, and baby weight were not different regardless of vitamin D deficiency (Table 2). Women with vitamin D deficiency tended to use insulin more frequently than those without vitamin D deficiency but the difference was not statistically significant.

The prevalence of postpartum glucose intolerance and overt diabetes was $44.8 \%$ and $4.9 \%$, respectively. Women with vitamin D deficiency at mid-pregnancy had a higher prevalence of postpartum glucose intolerance than did those without vitamin D deficiency ( $48.7 \%$ vs. $32.1 \%, P=0.011$ ) (Fig. 1). After postpartum 6 to 12 weeks, 0 and 30 minutes plasma glucose levels during 75-g OGTT were higher in women with vitamin D deficiency than in those without vitamin D deficiency but 60,90 ,

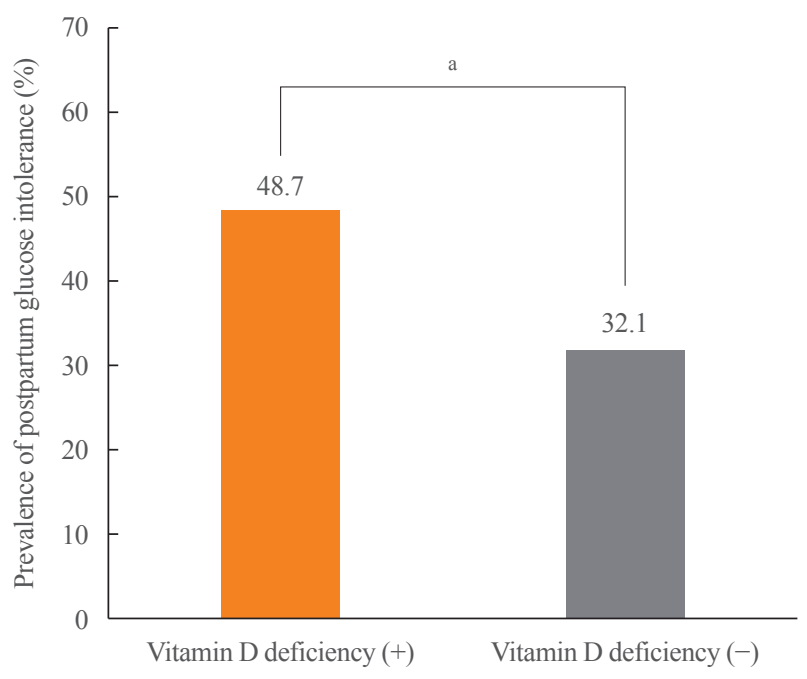

Fig. 1. Prevalence of postpartum glucose intolerance in women with gestational diabetes mellitus according to the status of serum 25-hydroxyvitamin D level. ${ }^{a} P<0.05$. and 120 minutes plasma glucose levels were not different (Table 3). HbAlc, fasting C-peptide, fasting insulin, HOMA-IR, and HOMA- $\beta$ were not different between the two groups, although HOMA- $\beta$ showed a low tendency in women with vitamin D deficiency.

Serum 25(OH)D level was negatively correlated with $\mathrm{HbA1c}$ antepartum and postpartum after being adjusted for maternal age, pre-pregnancy BMI, weight gain, blood pressure (systolic and diastolic), family history of diabetes, and season (antepartum: $r=-0.186, P=0.001$; postpartum: $r=-0.129, P=0.047$ ) (Table 4). No correlation was noted between serum 25(OH)D and HOMA-IR. Interestingly, after adjustment for the aforementioned factors, HOMA- $\beta$ was positively correlated with serum $25(\mathrm{OH}) \mathrm{D}$ level only postpartum $(r=0.138, P=0.035)$.

The risk of postpartum glucose intolerance was about twofold as high in women with vitamin D deficiency (Table 5). Even after adjustment for the aforementioned factors, the risk of postpartum glucose intolerance was still 2.00 times $(95 \%$ confidence interval $[\mathrm{CI}], 1.13$ to 3.55$)$ higher in women with vitamin $\mathrm{D}$ deficiency than in those without vitamin $\mathrm{D}$ deficiency $(P=$ $0.018)$.

\section{DISCUSSION}

Vitamin D deficiency is common in pregnant women and is a well-known risk factor for developing GDM [17-22]. Because women with GDM have an increased risk of conversion to type 2 diabetes over time, we should manage them carefully and appropriately after delivery. However, few studies have examined the effect of vitamin D deficiency at mid-pregnancy on postpartum glucose intolerance in women with GDM. We have found

Table 2. Pregnancy Outcomes of Women with Gestational Diabetes Mellitus According to Serum 25(OH)D Level

\begin{tabular}{lccc}
\hline Variable & Serum $25(\mathrm{OH}) \mathrm{D}<20 \mathrm{ng} / \mathrm{dL}(n=267)$ & Serum $25(\mathrm{OH}) \mathrm{D} \geq 20 \mathrm{ng} / \mathrm{dL}(n=81)$ & $P$ value \\
\hline Gestational age at delivery, wk $^{\mathrm{a}}$ & $38.3 \pm 1.7$ & $38.5 \pm 2.2$ & 0.543 \\
Preterm delivery $^{\mathrm{a}}$ & $38(14.5)$ & $33(14.1)$ & 1.000 \\
Cesarean section $^{\mathrm{b}}$ & $116(48.7)$ & & 0.688 \\
Treatment of GDM & $221(82.8)$ & $73(90.1)$ & 0.211 \\
$\quad$ Diet and exercise only & $40(15.0)$ & $6(7.4)$ & $2(2.5)$ \\
$\quad$ Insulin & $6(2.2)$ & $3121.4 \pm 421.6$ & 0.708 \\
$\quad$ Metformin & $3097.7 \pm 508.6$ & & \\
Neonate weight, g &
\end{tabular}

Values are expressed as mean \pm standard deviation or number $(\%)$.

25(OH)D, 25-hydroxyvitamin D; GDM, gestational diabetes mellitus.

${ }^{a}$ Preterm delivery information was missing for eight participants; ${ }^{b}$ Cesarean section information was missing for 38 participants. 


\begin{tabular}{|c|c|c|c|}
\hline Characteristic & Serum $25(\mathrm{OH}) \mathrm{D}<20 \mathrm{ng} / \mathrm{dL}(n=267)$ & Serum $25(\mathrm{OH}) \mathrm{D} \geq 20 \mathrm{ng} / \mathrm{dL}(n=81)$ & $P$ value \\
\hline \multicolumn{4}{|l|}{ 75-g OGTT } \\
\hline 0 min plasma glucose, $\mathrm{mg} / \mathrm{dL}$ & $96.3 \pm 9.4$ & $93.7 \pm 9.0$ & 0.024 \\
\hline $30 \mathrm{~min}$ plasma glucose, $\mathrm{mg} / \mathrm{dL}$ & $155.4 \pm 24.6$ & $145.7 \pm 27.7$ & 0.016 \\
\hline 60 min plasma glucose, $\mathrm{mg} / \mathrm{dL}$ & $161.4 \pm 37.5$ & $152.8 \pm 34.3$ & 0.142 \\
\hline 90 min plasma glucose, $\mathrm{mg} / \mathrm{dL}$ & $150.4 \pm 40.7$ & $144.1 \pm 34.7$ & 0.314 \\
\hline 120 min plasma glucose, $\mathrm{mg} / \mathrm{dL}$ & $133.3 \pm 33.4$ & $126.2 \pm 30.7$ & 0.090 \\
\hline $\mathrm{HbAlc}, \%$ & $5.5 \pm 0.3$ & $5.4 \pm 0.3$ & 0.100 \\
\hline Fasting C-peptide, ng/mL & $1.51 \pm 0.65$ & $1.39 \pm 0.70$ & 0.145 \\
\hline Fasting insulin, $\mu \mathrm{U} / \mathrm{mL}$ & $5.38 \pm 5.22$ & $5.31 \pm 9.46$ & 0.929 \\
\hline HOMA-IR & $1.32 \pm 1.34$ & $1.31 \pm 2.81$ & 0.976 \\
\hline НОМА- $\beta$ & $57.2 \pm 49.3$ & $84.2 \pm 261.3$ & 0.360 \\
\hline
\end{tabular}

that vitamin D deficiency at mid-pregnancy is very common and is associated with an elevated risk of postpartum glucose intolerance in women with GDM.

Because many studies have shown that vitamin D deficiency has been associated with type 2 diabetes and metabolic syndrome, we could presume it might also be associated with GDM. Although there are still many conflicting results for the association between vitamin $\mathrm{D}$ deficiency and development of GDM [28], recent meta-analyses have reported that such an association indeed exists [29-32]. A meta-analysis of 26 studies found that vitamin D deficiency may be associated with an increased risk of GDM (odds ratio, 1.18; 95\% CI, 1.01 to 1.35; $P<0.001$ ) [32]. Clinicians should focus on preventing postpartum diabetes as well as preventing GDM development, since women with previous GDM have a more than seven-fold higher risk of developing postpartum diabetes than do those without GDM [33]. Until now, there was limited data about whether vitamin D deficiency is a risk factor for postpartum glucose intolerance in women with GDM. Although our study patients were neither many nor representative of the Korean population, they still could have shown that vitamin D deficiency increased the risk of developing postpartum glucose intolerance by 2-fold in women with GDM.

Several studies have shown that vitamin D supplementation during pregnancy is effective in preventing GDM as well as improving pregnancy outcomes [34,35]. Vitamin D co-supplementation with calcium or omega-3 fatty acids in women with GDM had beneficial effects on metabolic parameters such as FPG, HOMA-IR, quantitative insulin sensitivity check index, and lipid profiles [36,37]. However, the effect of prenatal vitamin D supplements on postpartum glucose metabolism has rarely been studied. A study by Valizadeh et al. [38] reported that vitamin D3 (700,000 IU total) safely increased the serum 25(OH)D but had no influence in the plasma glucose level or insulin resistance at postpartum, perhaps because the treatment period was relatively short due to pregnancy. In a non-pregnant population, vitamin D3 supplementation (4,000 IU daily) for 6 months (720,000 IU total) improved insulin resistance even though there was no difference in the first 3 months [39]. To prevent postpartum glucose intolerance, vitamin D supplementation during the entire pregnancy period may be necessary. It is not conclusive yet whether vitamin D supplementation is helpful to women with GDM because there is no large randomized controlled trial.

In a normal non-pregnant individual, approximately $85 \%$ of serum $25(\mathrm{OH}) \mathrm{D}$ is bound to vitamin $\mathrm{D}$ binding protein (DBP), $15 \%$ is bound to albumin, only $0.03 \%$ is free [40]. During pregnancy, DBP is almost 2-fold increases between the second and third trimesters like other globulins. However, mean free $25(\mathrm{OH}) \mathrm{D}$ may be the same as or only slightly lower than in non-pregnant women despite these marked DBP changes through decreasing affinity of DBP for vitamin D [41,42]. Consequently, there would be no differences of vitamin $\mathrm{D}$ activity for insulin resistance and insulin secretion between pregnant 
Table 4. Correlations between Serum 25-Hydroxyvitamin D Levels and Glycemic Parameters

\begin{tabular}{|c|c|c|c|c|}
\hline \multirow{2}{*}{ Variable } & \multicolumn{2}{|c|}{ Unadjusted } & \multicolumn{2}{|c|}{ Adjusted } \\
\hline & $r$ & $P$ value & $r$ & $P$ value \\
\hline \multicolumn{5}{|l|}{ Antepartum period } \\
\hline Plasma glucose at 50-g OGTT, mg/dL & -0.031 & 0.571 & -0.032 & 0.564 \\
\hline \multicolumn{5}{|l|}{ 100-g OGTT } \\
\hline 0 min plasma glucose, $\mathrm{mg} / \mathrm{dL}$ & -0.011 & 0.831 & 0.008 & 0.891 \\
\hline 60 min plasma glucose, $\mathrm{mg} / \mathrm{dL}$ & 0.046 & 0.393 & 0.011 & 0.838 \\
\hline 120 min plasma glucose, $\mathrm{mg} / \mathrm{dL}$ & 0.031 & 0.565 & -0.140 & 0.011 \\
\hline 180 min plasma glucose, $\mathrm{mg} / \mathrm{dL}$ & -0.058 & 0.280 & -0.186 & 0.001 \\
\hline HbAlc, $\%$ & -0.266 & $<0.001$ & -0.186 & 0.001 \\
\hline Fasting C-peptide, ng/mL & -0.084 & 0.117 & 0.019 & 0.725 \\
\hline Fasting insulin, $\mu \mathrm{U} / \mathrm{mL}$ & -0.111 & 0.039 & 0.010 & 0.849 \\
\hline HOMA-IR & -0.092 & 0.088 & 0.017 & 0.751 \\
\hline НОМА- $\beta$ & -0.113 & 0.035 & 0.041 & 0.461 \\
\hline \multicolumn{5}{|l|}{ Postpartum period } \\
\hline \multicolumn{5}{|l|}{ 75-g OGTT } \\
\hline 0 min plasma glucose, $\mathrm{mg} / \mathrm{dL}$ & -0.151 & 0.005 & -0.158 & 0.015 \\
\hline $30 \mathrm{~min}$ plasma glucose, $\mathrm{mg} / \mathrm{dL}$ & -0.168 & 0.009 & -0.174 & 0.007 \\
\hline 60 min plasma glucose, $\mathrm{mg} / \mathrm{dL}$ & -0.116 & 0.071 & -0.091 & 0.165 \\
\hline 90 min plasma glucose, $\mathrm{mg} / \mathrm{dL}$ & -0.119 & 0.063 & -0.103 & 0.114 \\
\hline 120 min plasma glucose, $\mathrm{mg} / \mathrm{dL}$ & -0.129 & 0.016 & -0.147 & 0.024 \\
\hline $\mathrm{HbAlc}, \%$ & -0.129 & 0.017 & -0.129 & 0.047 \\
\hline Fasting C-peptide, ng/mL & -0.112 & 0.037 & -0.027 & 0.676 \\
\hline Fasting insulin, $\mu \mathrm{U} / \mathrm{mL}$ & -0.004 & 0.936 & -0.049 & 0.450 \\
\hline HOMA-IR & -0.004 & 0.943 & -0.075 & 0.248 \\
\hline НОМА- $\beta$ & 0.081 & 0.134 & 0.138 & 0.035 \\
\hline
\end{tabular}

Adjusted for maternal age, pre-pregnancy body mass index, weight gain, family history of diabetes, blood pressure (systolic and diastolic), and season. OGTT, oral glucose tolerance test; HbA1c, hemoglobin A1c; HOMA-IR, homeostasis model assessment of insulin resistance; HOMA- $\beta$, homeostasis model assessment of $\beta$-cell function.

Table 5. OR for Postpartum Glucose Intolerance According to Serum 25(OH)D Level in Pregnancy

\begin{tabular}{|c|c|c|c|c|}
\hline Vitamin D status & Unadjusted OR (95\% CI) & $P$ value & Adjusted OR (95\% CI) & $P$ value \\
\hline Serum $25(\mathrm{OH}) \mathrm{D} \geq 20 \mathrm{ng} / \mathrm{dL}$ & Reference & & Reference & \\
\hline Serum $25(\mathrm{OH}) \mathrm{D}<20 \mathrm{ng} / \mathrm{dL}$ & $2.01(1.19-3.39)$ & 0.009 & $2.00(1.13-3.55)$ & 0.018 \\
\hline
\end{tabular}

Adjusted for maternal age, pre-pregnancy body mass index, weight gain, family history of diabetes, blood pressure (systolic and diastolic), and season. OR, odds ratio; 25(OH)D, 25-hydroxyvitamin D; CI, confidence interval.

and non-pregnant women. Furthermore, in this study, serum albumin concentration was not different between GDM women with and without vitamin D deficiency. We could assume that albumin or other globulins were not influenced to the results of this study.
In this study, HOMA- $\beta$ was positively correlated with serum $25(\mathrm{OH}) \mathrm{D}$ level only postpartum. One possible mechanism is that vitamin $\mathrm{D}$ has a direct effect on the performance of the $\beta$-cells of the pancreas $[7,43]$, so that vitamin D might enhance insulin secretion. The other possible mechanism is that vitamin 
D may affect intracellular calcium regulation which plays an important role in the insulin-mediated intracellular processes of insulin-receptor tissue $[32,44,45]$. Interestingly, HOMA- $\beta$ at mid-pregnancy was significantly higher in women with vitamin D deficiency than those without vitamin D deficiency. This might be compensatory hypersecretion of insulin to overcome elevated insulin resistance in GDM women with vitamin D deficiency [23-25]. At postpartum period, HOMA- $\beta$ was not different although it was numerically low in women with vitamin D deficiency than those without vitamin $\mathrm{D}$ deficiency.

Some limitations need to be considered in the interpretation of our findings. First, we cannot generalize these results to other ethnic populations. In Korea, approximately $90 \%$ of women are not vitamin D sufficient [19]. Second, we did not measure serum $25(\mathrm{OH}) \mathrm{D}$ postpartum. Third, dietary vitamin D intake could not be adjusted because we had no food frequency questionnaire data. Finally, the study population was neither large nor representative of the Korean population, so large prospective studies are needed to confirm these results. This study, however, might be valuable because it evaluated the association between vitamin D status in mid-pregnancy and postpartum glucose intolerance in women with GDM.

In conclusion, vitamin D deficiency at mid-pregnancy is associated with an elevated risk of postpartum glucose intolerance in women with GDM. Consequently, we should try to figure out postpartum glucose intolerance if women with GDM have vitamin D deficiency at mid-pregnancy.

\section{CONFLICTS OF INTEREST}

No potential conflict of interest relevant to this article was reported.

\section{AUTHOR CONTRIBUTIONS}

Conception or design: K.S.K., S.K.K. Acquisition, analysis, or interpretation of data: K.S.K., S.W.P., Y.W.C., S.K.K. Drafting the work or revising: K.S.K., S.W.P., Y.W.C., S.K.K. Final approval of the manuscript: K.S.K., S.K.K.

\section{ORCID}

Kyung-Soo Kim https://orcid.org/0000-0002-7738-2284

Soo-Kyung Kim https://orcid.org/0000-0002-2601-3438

\section{REFERENCES}

1. Isaia G, Giorgino R, Adami S. High prevalence of hypovitaminosis D in female type 2 diabetic population. Diabetes Care 2001;24:1496.

2. Targher G, Bertolini L, Padovani R, Zenari L, Scala L, Cigolini M, et al. Serum 25-hydroxyvitamin D3 concentrations and carotid artery intima-media thickness among type 2 diabetic patients. Clin Endocrinol (Oxf) 2006;65:593-7.

3. Rhee SY, Hwang YC, Chung HY, Woo JT. Vitamin D and diabetes in Koreans: analyses based on the Fourth Korea National Health and Nutrition Examination Survey (KNHANES), 2008-2009. Diabet Med 2012;29:1003-10.

4. Lim S, Kim MJ, Choi SH, Shin CS, Park KS, Jang HC, et al. Association of vitamin D deficiency with incidence of type 2 diabetes in high-risk Asian subjects. Am J Clin Nutr 2013;97:524-30.

5. Zhang D, Seo DH, Choi HS, Park HS, Chung YS, Lim SK. Effects of single vitamin $\mathrm{D}_{3}$ injection (200,000 Units) on serum fibroblast growth factor 23 and sclerostin levels in subjects with vitamin D deficiency. Endocrinol Metab (Seoul) 2017;32:451-9.

6. Hong YJ, Kang ES, Ji MJ, Choi HJ, Oh T, Koong SS, et al. Association between Bsm1 polymorphism in vitamin D receptor gene and diabetic retinopathy of type 2 diabetes in Korean population. Endocrinol Metab (Seoul) 2015;30:46974.

7. Chiu KC, Chu A, Go VL, Saad MF. Hypovitaminosis D is associated with insulin resistance and beta cell dysfunction. Am J Clin Nutr 2004;79:820-5.

8. Kayaniyil S, Vieth R, Retnakaran R, Knight JA, Qi Y, Gerstein HC, et al. Association of vitamin D with insulin resistance and beta-cell dysfunction in subjects at risk for type 2 diabetes. Diabetes Care 2010;33:1379-81.

9. Nikooyeh B, Neyestani TR, Farvid M, Alavi-Majd H, Houshiarrad A, Kalayi A, et al. Daily consumption of vitamin D- or vitamin D + calcium-fortified yogurt drink improved glycemic control in patients with type 2 diabetes: a randomized clinical trial. Am J Clin Nutr 2011;93:764-71.

10. Tabesh M, Azadbakht L, Faghihimani E, Tabesh M, Esmaillzadeh A. Effects of calcium-vitamin D co-supplementation on metabolic profiles in vitamin D insufficient people with type 2 diabetes: a randomised controlled clinical trial. Diabetologia 2014;57:2038-47.

11. Jehle S, Lardi A, Felix B, Hulter HN, Stettler C, Krapf R. Effect of large doses of parenteral vitamin D on glycaemic 
control and calcium/phosphate metabolism in patients with stable type 2 diabetes mellitus: a randomised, placebo-controlled, prospective pilot study. Swiss Med Wkly 2014;144: w13942.

12. Jorde R, Figenschau Y. Supplementation with cholecalciferol does not improve glycaemic control in diabetic subjects with normal serum 25-hydroxyvitamin D levels. Eur J Nutr 2009;48:349-54.

13. Sadiya A, Ahmed SM, Carlsson M, Tesfa Y, George M, Ali $\mathrm{SH}$, et al. Vitamin D supplementation in obese type 2 diabetes subjects in Ajman, UAE: a randomized controlled double-blinded clinical trial. Eur J Clin Nutr 2015;69:707-11.

14. American Diabetes Association. 2. Classification and diagnosis of diabetes: standards of medical care in diabetes-2019. Diabetes Care 2019;42:S13-28.

15. Jeon EJ, Hong SY, Lee JH. Adipokines and insulin resistance according to characteristics of pregnant women with gestational diabetes mellitus. Diabetes Metab J 2017;41: 457-65.

16. Yang SH, Kim C, An HS, An H, Lee JS. Prediction of gestational diabetes mellitus in pregnant Korean women based on abdominal subcutaneous fat thickness as measured by ultrasonography. Diabetes Metab J 2017;41:486-91.

17. Hollis BW, Wagner CL. Nutritional vitamin D status during pregnancy: reasons for concern. CMAJ 2006;174:1287-90.

18. Bodnar LM, Simhan HN, Powers RW, Frank MP, Cooperstein E, Roberts JM. High prevalence of vitamin D insufficiency in black and white pregnant women residing in the northern United States and their neonates. J Nutr 2007;137: 447-52.

19. Choi HS. Vitamin d status in Korea. Endocrinol Metab (Seoul) 2013;28:12-6.

20. Zhang C, Qiu C, Hu FB, David RM, van Dam RM, Bralley A, et al. Maternal plasma 25-hydroxyvitamin D concentrations and the risk for gestational diabetes mellitus. PLoS One 2008;3:e3753.

21. Maghbooli Z, Hossein-Nezhad A, Karimi F, Shafaei AR, Larijani B. Correlation between vitamin D3 deficiency and insulin resistance in pregnancy. Diabetes Metab Res Rev 2008;24:27-32.

22. Lacroix M, Battista MC, Doyon M, Houde G, Menard J, Ardilouze JL, et al. Lower vitamin D levels at first trimester are associated with higher risk of developing gestational diabetes mellitus. Acta Diabetol 2014;51:609-16.

23. Jang HC. Gestational diabetes in Korea: incidence and risk factors of diabetes in women with previous gestational dia- betes. Diabetes Metab J 2011;35:1-7.

24. Xiang AH, Takayanagi M, Black MH, Trigo E, Lawrence $\mathrm{JM}$, Watanabe RM, et al. Longitudinal changes in insulin sensitivity and beta cell function between women with and without a history of gestational diabetes mellitus. Diabetologia 2013;56:2753-60.

25. Kim C, Newton KM, Knopp RH. Gestational diabetes and the incidence of type 2 diabetes: a systematic review. Diabetes Care 2002;25:1862-8.

26. Moon JH, Kwak SH, Jang HC. Prevention of type 2 diabetes mellitus in women with previous gestational diabetes mellitus. Korean J Intern Med 2017;32:26-41.

27. Pisprasert V, Ingram KH, Lopez-Davila MF, Munoz AJ, Garvey WT. Limitations in the use of indices using glucose and insulin levels to predict insulin sensitivity: impact of race and gender and superiority of the indices derived from oral glucose tolerance test in African Americans. Diabetes Care 2013;36:845-53.

28. Schneuer FJ, Roberts CL, Guilbert C, Simpson JM, Algert CS, Khambalia AZ, et al. Effects of maternal serum 25-hydroxyvitamin D concentrations in the first trimester on subsequent pregnancy outcomes in an Australian population. Am J Clin Nutr 2014;99:287-95.

29. Aghajafari F, Nagulesapillai T, Ronksley PE, Tough SC, O'Beirne M, Rabi DM. Association between maternal serum 25-hydroxyvitamin D level and pregnancy and neonatal outcomes: systematic review and meta-analysis of observational studies. BMJ 2013;346:f1169.

30. Zhang MX, Pan GT, Guo JF, Li BY, Qin LQ, Zhang ZL. Vitamin D deficiency increases the risk of gestational diabetes mellitus: a meta-analysis of observational studies. Nutrients 2015;7:8366-75.

31. Lu M, Xu Y, Lv L, Zhang M. Association between vitamin D status and the risk of gestational diabetes mellitus: a metaanalysis. Arch Gynecol Obstet 2016;293:959-66.

32. Amraei M, Mohamadpour S, Sayehmiri K, Mousavi SF, Shirzadpour E, Moayeri A. Effects of vitamin D deficiency on incidence risk of gestational diabetes mellitus: a systematic review and meta-analysis. Front Endocrinol (Lausanne) 2018;9:7.

33. Bellamy L, Casas JP, Hingorani AD, Williams D. Type 2 diabetes mellitus after gestational diabetes: a systematic review and meta-analysis. Lancet 2009;373:1773-9.

34. Shahgheibi S, Farhadifar F, Pouya B. The effect of vitamin D supplementation on gestational diabetes in high-risk women: results from a randomized placebo-controlled trial. 
J Res Med Sci 2016;21:2.

35. Sablok A, Batra A, Thariani K, Batra A, Bharti R, Aggarwal $\mathrm{AR}$, et al. Supplementation of vitamin D in pregnancy and its correlation with feto-maternal outcome. Clin Endocrinol (Oxf) 2015;83:536-41.

36. Asemi Z, Karamali M, Esmaillzadeh A. Effects of calciumvitamin D co-supplementation on glycaemic control, inflammation and oxidative stress in gestational diabetes: a randomised placebo-controlled trial. Diabetologia 2014;57: 1798-806.

37. Jamilian M, Samimi M, Ebrahimi FA, Hashemi T, Taghizadeh M, Razavi M, et al. The effects of vitamin D and omega-3 fatty acid co-supplementation on glycemic control and lipid concentrations in patients with gestational diabetes. J Clin Lipidol 2017;11:459-68.

38. Valizadeh M, Piri Z, Mohammadian F, Kamali K, Amir Moghadami HR. The impact of vitamin D supplementation on post-partum glucose tolerance and insulin resistance in gestational diabetes: a randomized controlled trial. Int J Endocrinol Metab 2016;14:e34312.

39. von Hurst PR, Stonehouse W, Coad J. Vitamin D supplementation reduces insulin resistance in South Asian women living in New Zealand who are insulin resistant and vitamin D deficient: a randomised, placebo-controlled trial. $\mathrm{Br} \mathrm{J}$
Nutr 2010;103:549-55.

40. Bikle DD, Schwartz J. Vitamin D binding protein, total and free vitamin D levels in different physiological and pathophysiological conditions. Front Endocrinol (Lausanne) 2019; 10:317.

41. Schwartz JB, Gallagher JC, Jorde R, Berg V, Walsh J, Eastell $\mathrm{R}$, et al. Determination of free $25(\mathrm{OH}) \mathrm{D}$ concentrations and their relationships to total $25(\mathrm{OH}) \mathrm{D}$ in multiple clinical populations. J Clin Endocrinol Metab 2018;103:3278-88.

42. Tsuprykov O, Buse C, Skoblo R, Haq A, Hocher B. Reference intervals for measured and calculated free 25-hydroxyvitamin D in normal pregnancy. J Steroid Biochem Mol Biol 2018;181:80-87.

43. Norman AW, Frankel JB, Heldt AM, Grodsky GM. Vitamin $D$ deficiency inhibits pancreatic secretion of insulin. Science 1980;209:823-5.

44. Draznin B, Sussman KE, Eckel RH, Kao M, Yost T, Sherman NA. Possible role of cytosolic free calcium concentrations in mediating insulin resistance of obesity and hyperinsulinemia. J Clin Invest 1988;82:1848-52.

45. Alvarez JA, Ashraf A. Role of vitamin d in insulin secretion and insulin sensitivity for glucose homeostasis. Int J Endocrinol 2010;2010:351385. 